\title{
EXPERIMENTAL ANALYSIS OF TURBOCHARGER MAXIMUM SPEED USING DIFFERENT MATERIALS FOR COMPRESSOR IMPELLER
}

\author{
Fábio B. Bassetti \\ Cummins Turbo Technologies \\ E-mails: fabio.bassetti@cummins.com
}

\begin{abstract}
Modern diesel engines for vehicular applications such as buses and other commercial vehicles are increasingly using technological resources in order to meet the pollutant emissions regulations. Among these features, the turbocharger fulfills an essential function of providing a higher air flow to the engine intake, providing a cleaner and more efficient combustion.

During the application process of a turbocharger, calculations are performed to estimate the life of the compressor impeller, which takes into account the maximum shaft speed and the number of cycles that cause fatigue damage. Among these parameters, the maximum speed affects directly in the fatigue life of the impeller. Due to the different material options for the compressor impeller, the mass properties of each type of rotor may result in differences in their inertias thus impacting the maximum speed and the fatigue life calculation.
\end{abstract}

The objective of this study is to provide a comparison of inertias influence for two choices of materials and check the maximum speed behavior with the variation of altitude during experimental tests. The experimental data were gathered in a delivery truck with a GVW of 8 tons, equipped with 4-cylinder engine, while traveling on a route from Guarulhos (ca. 650m alt.) up to Campos de Jordao (ca. 1700m alt.) in the state of Sao Paulo, Brazil.

\section{INTRODUCTION}

Environmental issues are being addressed on a global scale. Given these circumstances, the need for enhanced automotive fuel economy has grown rapidly in recent years, from the perspective of not only reduction of tailpipe emissions but also $\mathrm{CO} 2$ reduction. A variety of approaches have been examined in the history of automotive fuel economy enhancement technologies. One prominent approach is to reduce engine displacement, based on the "downsizing concept", by means of super-charging. Turbochargers are playing an important role on the achievement of emission regulations for internal combustion engines because they enable reducing engine displacement without lowering output performance. The reduction of displacement leads to lower frictional and pumping losses thus supercharged engines exhibit better fuel economy performance compared to naturally aspirated engines of the same output [1]. However, to fully explore the potential, some problems must be overcome during the development of the engines [2]. Actually, the higher compression temperature and pressure tend to reduce the ignition delay period, and consequently improve the combustion characteristics with a given fuel or to allow the use of fuel of poorer ignition quality. On the 
other hand, depending on the application , the limits on specific output of supercharged diesel engines would be set chiefly by considerations of reliability and durability [3]. This means that the specification of the turbocharger itself would be dependent on the expected B10 life or/and failure rate/year as per customer specification.

One of the alternatives to overcome durability problems, mainly related to low-cycle fatigue events, is to change compressor impeller material specification. This is necessary when high compressor pressure ratios (of the order of 4:1 and higher) are needed, resulting in high tip speeds, thus causing the wheel to have high temperatures near the exducer (outlet) of the wheel and high stresses [4].

The main material options widely used by Cummins Turbo Technologies are the cast aluminum impeller and the machined from solid (wrought) aluminum impeller. Cast aluminum remains the most common material used for turbocharger impellers due to its relatively high strength to weight ratio and the low resulting compressor wheel inertia. The most common casting method for producing aluminum impellers employs a foamed plaster mould produced from a rubber pattern. The use of a foamed plaster mould increases the ability to cast thin sections by drawing a vacuum through the mould. Cast impellers are almost exclusively produced using an Al-Si-Cu-Mg aluminum casting alloy by this process using an atmospheric pressure furnace, which is shown in Figure 1. The casting is produced by lowering the pressure in the mould cavity, which in turn induces the molten aluminum to fill the mould cavity under atmospheric pressure. One of the drawbacks of cast impellers is that the casting process can lead to the formation of casting defects, which can reduce the durability of the impeller.

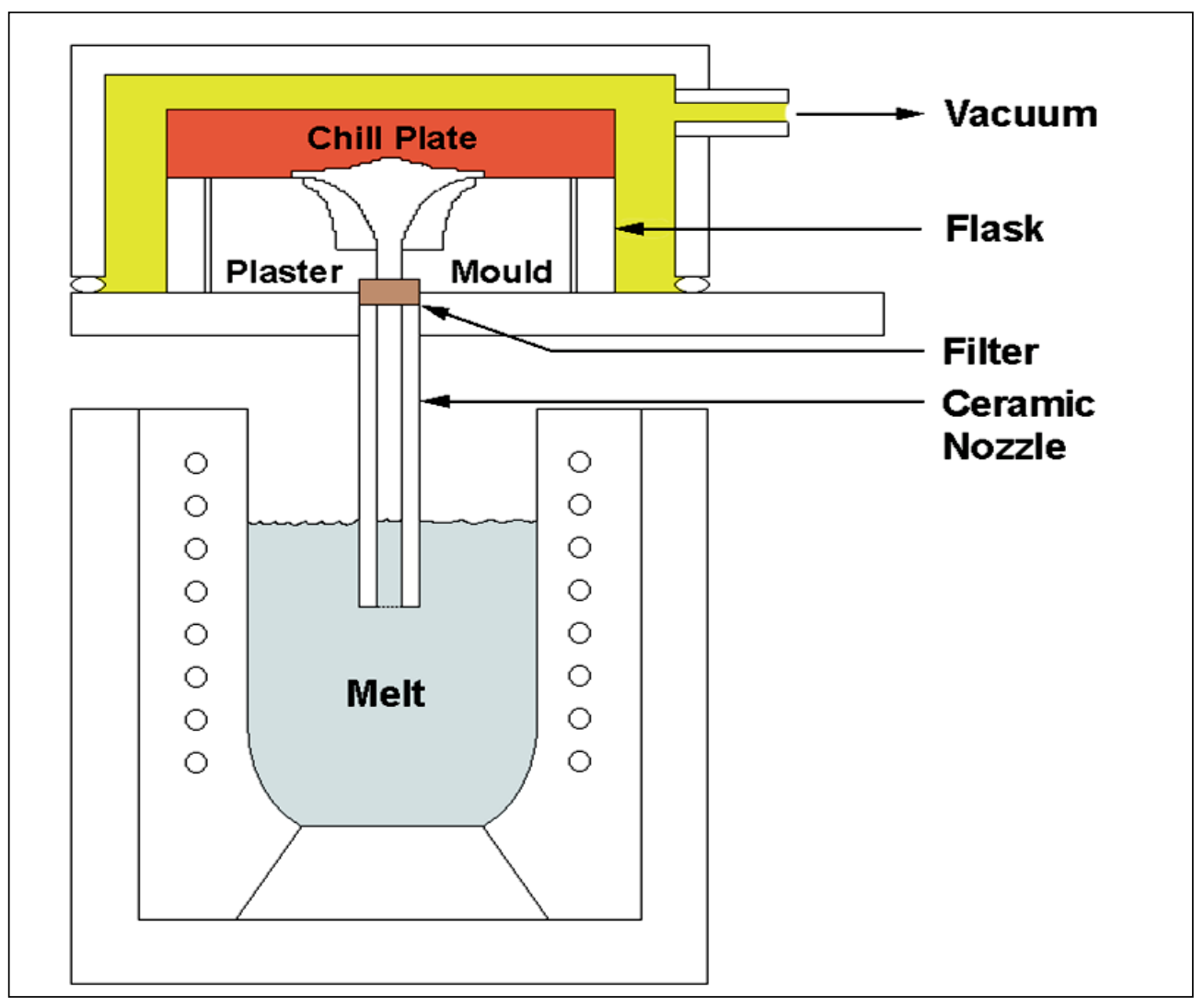

Figure 1: Cast aluminum impeller manufacturing process. 
Cast aluminum cannot normally achieve the same durability as wrought aluminum for turbocharger impellers. Wrought alloys are mechanically processed, which breaks down Cast aluminum cannot normally achieve the same durability as wrought aluminum for turbocharger impellers. Wrought alloys are mechanically processed, which breaks down any defects that might be present and refines the grain structure to improve the fatigue properties. There is typically an order of magnitude difference in the grain size of cast and wrought alloys. It is also possible to have a higher content of alloying elements in a wrought aluminum component, which further improves its fatigue properties. Machined from solid (MFS) impellers were first introduced in Cummins Turbo Technologies turbochargers in 2002 for highly cyclical applications; for example, stop-start city bus operation where there were additional durability challenges. A large percentage of Cummins Turbo Technologies aluminum impellers are now MFS and are produced using state-of-the-art high speed five-axis milling machines in a solid piece of wrought aluminum, resulting in the final design and shape of the impeller [5]. Figure 2 shows a comparison of surface finish in these impellers against the Cast version.

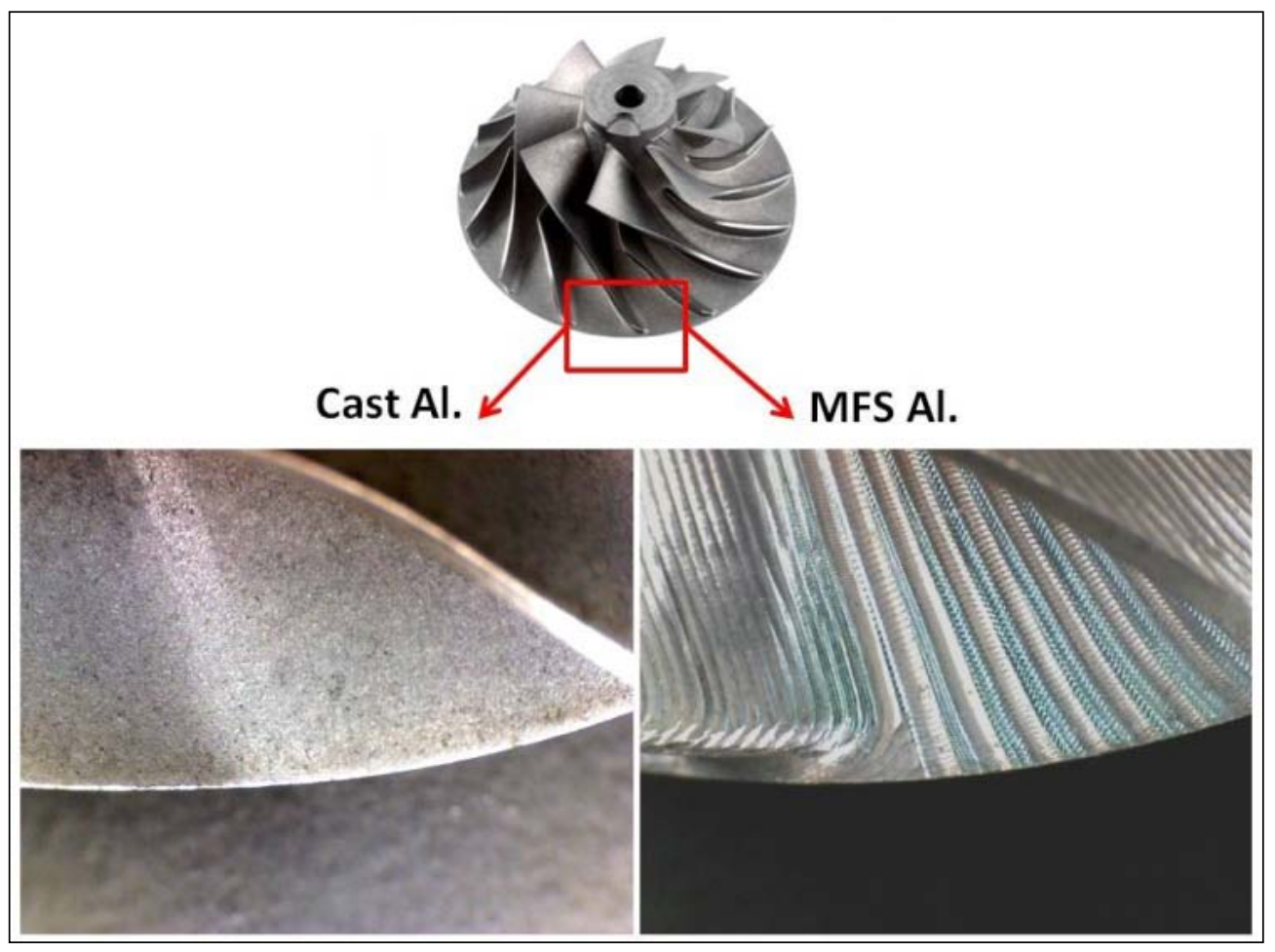

Figure 2: Surface finish comparison between Cast Al and MFS.

\section{METHOD}

For reasons of confidentiality, all data are presented as function of normalized speed, as per equation 1:

$\mathrm{n}_{\text {turbo }}=\frac{n}{\mathrm{n}_{\text {máx turbo }}}$

The vehicle used in the comparison is a delivery truck with GVW of 8t, using an in-line configuration 4 cylinders engine with 16 valves, compliant with Conama Proconve P7 [6], 
which was implemented in January 2012 in Brazil and is equivalent to Euro V, as shown at Figure 3.

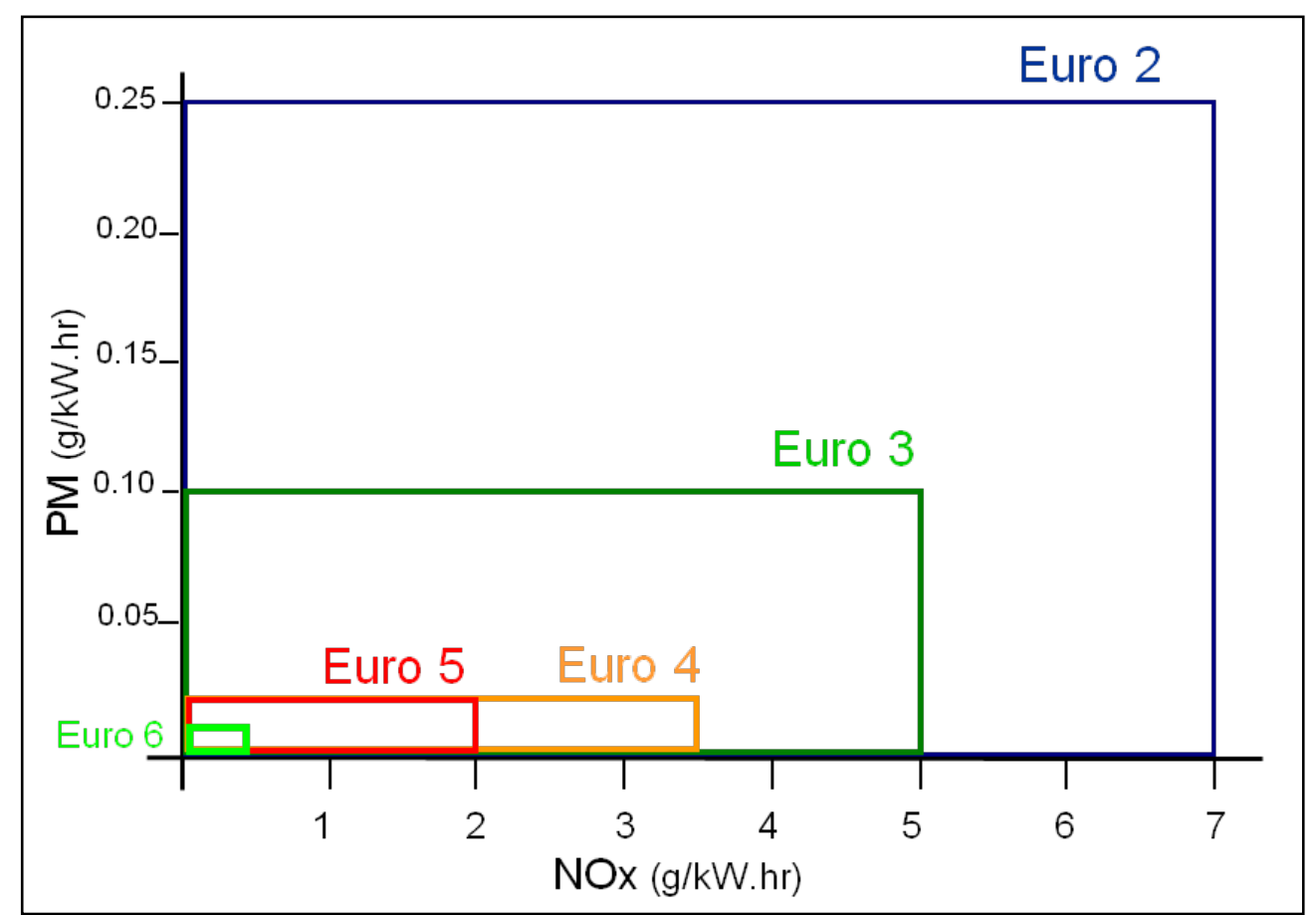

Figure 3: Emissions targets for particulate matter and NOx, for each program phase.

The two chosen options for compressor impeller material are:

Option A - Machined from solid (wrought) aluminum;

Option B - Cast aluminum.

These options are the most widely used in Commercial Automotive applications, by Cummins Turbo Technologies, and avoid the use of much expensive materials such as Titanium. From the design point-of-view, both impellers have the same dimensions and tolerances, except for the surface finish which is different due to different manufacturing process. Although different, this effect will not be considered into the calculations due to low impact in airflow.

Tests were performed on the route Guarulhos - Campos de Jordao. Most of the route consists of plain highway, until reaching the beginning of the uphill sector. This section, as can be seen on Figure 4, present almost constant steepness from $650 \mathrm{~m}$ up to $1650 \mathrm{~m}$ of altitude, which is ideal for the comparison of the compressor impeller because of the higher load applied to the vehicle and because of the widest range of altitude variation. Only the data from the uphill sector will be used for the following analysis. 


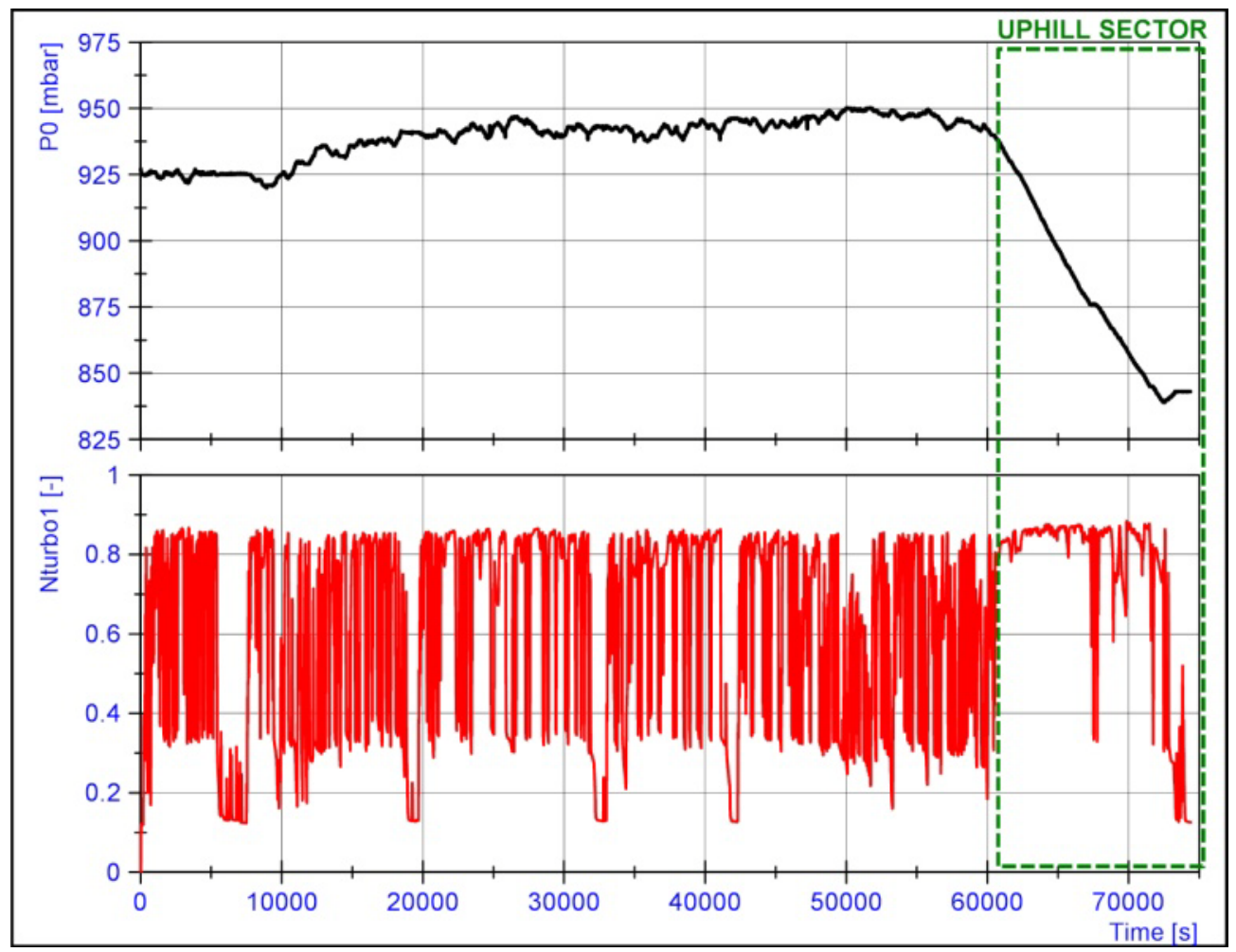

Figure 4: As-logged data from both impeller options.

The logged data from the specified routes consisted of the following points, recorded with rate of $10 \mathrm{~Hz}$ :

P1 - Compressor inlet pressure;

T1 - Compressor inlet temperature;

P2 - Compressor outlet pressure;

T2 - Compressor outlet temperature;

P3 - Turbine inlet pressure;

T3 - Turbine inlet temperature;

P4 - Turbine outlet pressure;

T4 - Turbine outlet temperature;

$\mathrm{n}_{\text {turbo }}$ - Turbocharger shaft speed;

$\mathrm{n}_{\text {engine }}$ - Engine speed;

P0 - Barometric pressure;

T0 - Ambient temperature.

The pressure and temperatures channels, from points 1 to 4 , were compared, in order to validate that both recordings were similar, mainly due to uncontrollable factors such as traffic or any environmental conditions. For the following statistical analysis it was used mainly the turbocharger shaft speed and barometric pressure. Figure 5 shows a generic engine scheme, representing each logged point. 


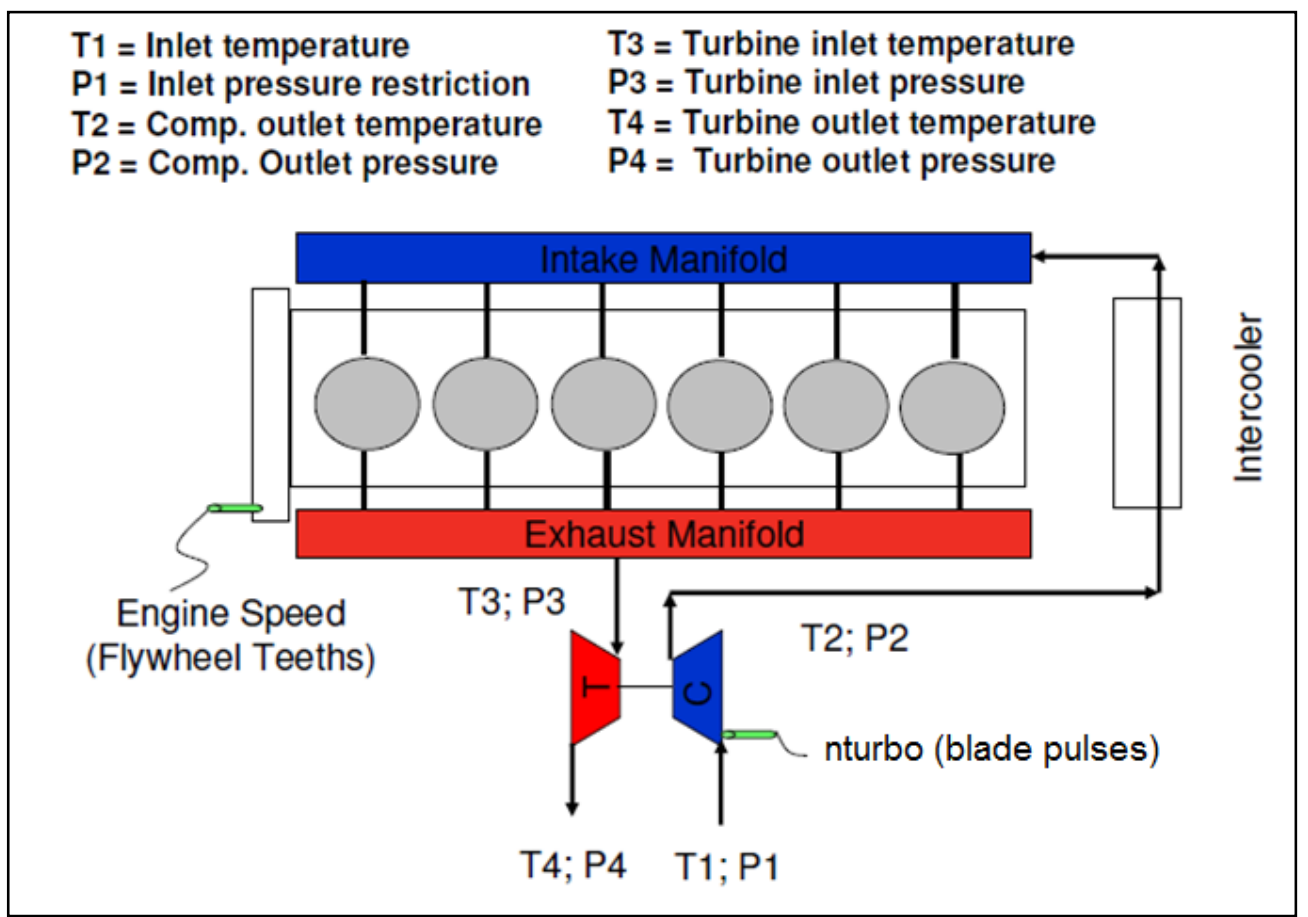

Figure 5: Engine scheme showing measurement points.

\section{DATA ANALYSIS}

As can be seen on Figure 6, all logged data are recorded as a function of time, which requires a post-process filter and arrangement to enable statistical analysis and regression.

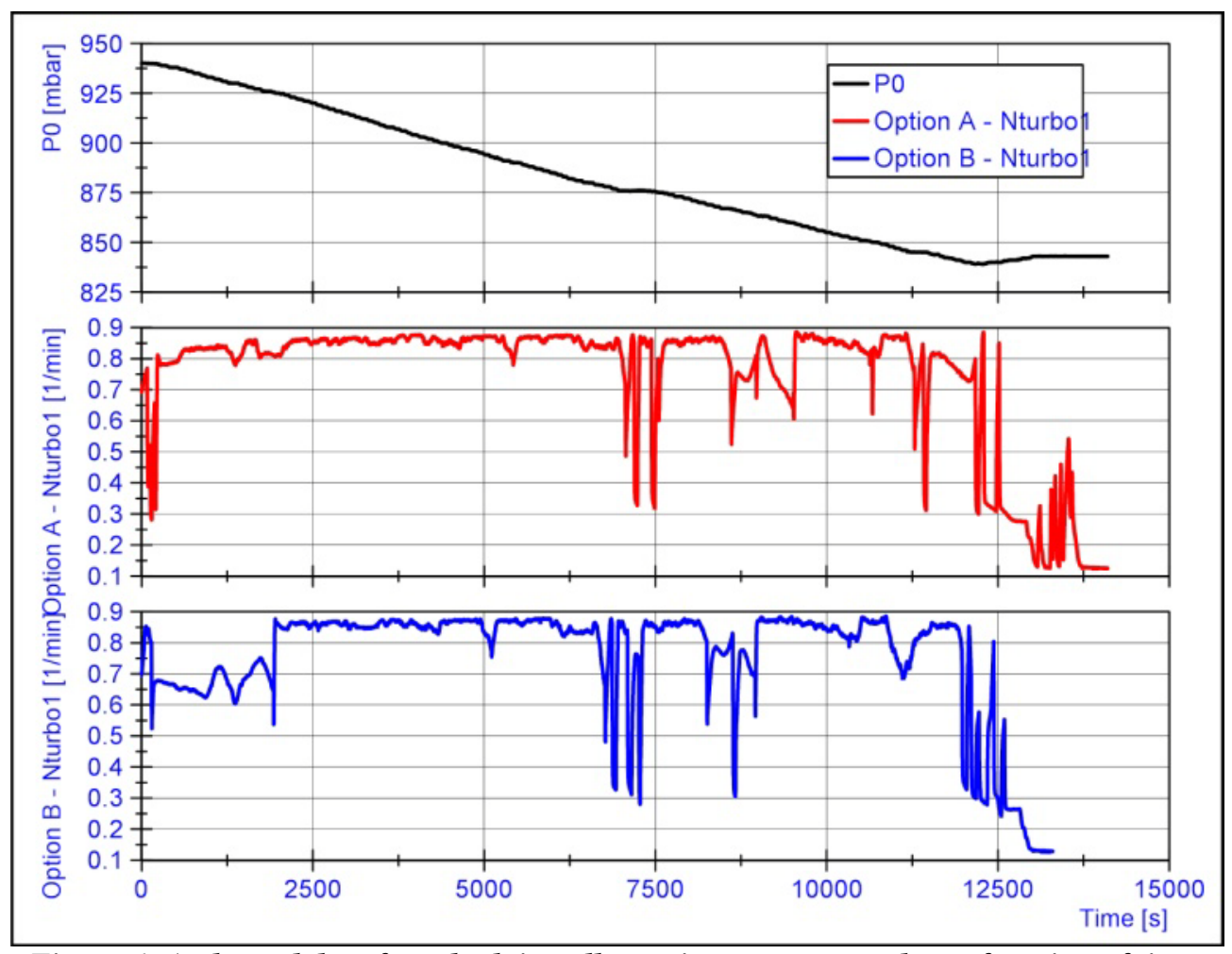

Figure 6: As-logged data from both impeller options, represented as a function of time. 
Hence, for each impeller option, all gathered data (points) for turbocharger shaft speeds recorded at the same ambient pressure were grouped. This process allows creating a table with ambient pressure in steps of 5 mbar versus all the turbocharger shaft speeds points.

The next step is to take the 10 (ten) highest points of turbocharger shaft speed for each ambient pressure and find the median values. Then, regressions (fitted line plot) by linear and cubic models were performed, with r-squared factor calculated. This factor shows how much variation a model have in comparison with the original data points; e.g., a factor of 1.0 would mean that the model fits perfectly into all original points. It is expected at least a 0.90 factor as general criteria.

Taking into account the model for each impeller material, a calculation of the correction factor is performed, which shows how much increase of turbocharger shaft speed for each $1000 \mathrm{~m}$ increase of altitude. This factor is essential for the B10 life calculation of the impeller, as well as estimated failure rate per year, according to vehicle usage. It also helps on the prediction of performance when the vehicle is operating in a different geographic market.

\section{RESULTS}

From the as-logged data, which is in function of time, all turbocharger shaft speed is grouped for the same ambient pressure and the 10 highest values were summarized into a median value. The Table 1 shows the summary of all highest turbocharger shaft speeds by ambient pressure, for both impeller options.

Table 1: Median values of maximum turbocharger shaft speed, for both impeler options

\begin{tabular}{|c|c|c|c|}
\hline Pressure & Altitude & $\begin{array}{c}\text { Option A } \\
\text { (MFS Al.) }\end{array}$ & $\begin{array}{c}\text { Option B } \\
\text { (Cast Al.) }\end{array}$ \\
\hline P0 [mbar] & Alt [m] & $\mathrm{N}_{\text {turbo }}[-]$ & $\mathrm{N}_{\text {turbo }}[-]$ \\
\hline 920 & 930 & 0.866747 & 0.868729 \\
\hline 915 & 975 & 0.867801 & 0.869920 \\
\hline 900 & 1110 & 0.870965 & 0.873494 \\
\hline 895 & 1155 & 0.872019 & 0.874685 \\
\hline 890 & 1200 & 0.873074 & 0.875876 \\
\hline 885 & 1245 & 0.874128 & 0.877067 \\
\hline 880 & 1290 & 0.875183 & 0.878259 \\
\hline 850 & 1560 & 0.881510 & 0.885406 \\
\hline
\end{tabular}

For each impeller option a regression was performed, considering either liner or cubic models. The result for each model is showed on Figure 7 and Figure 8. 


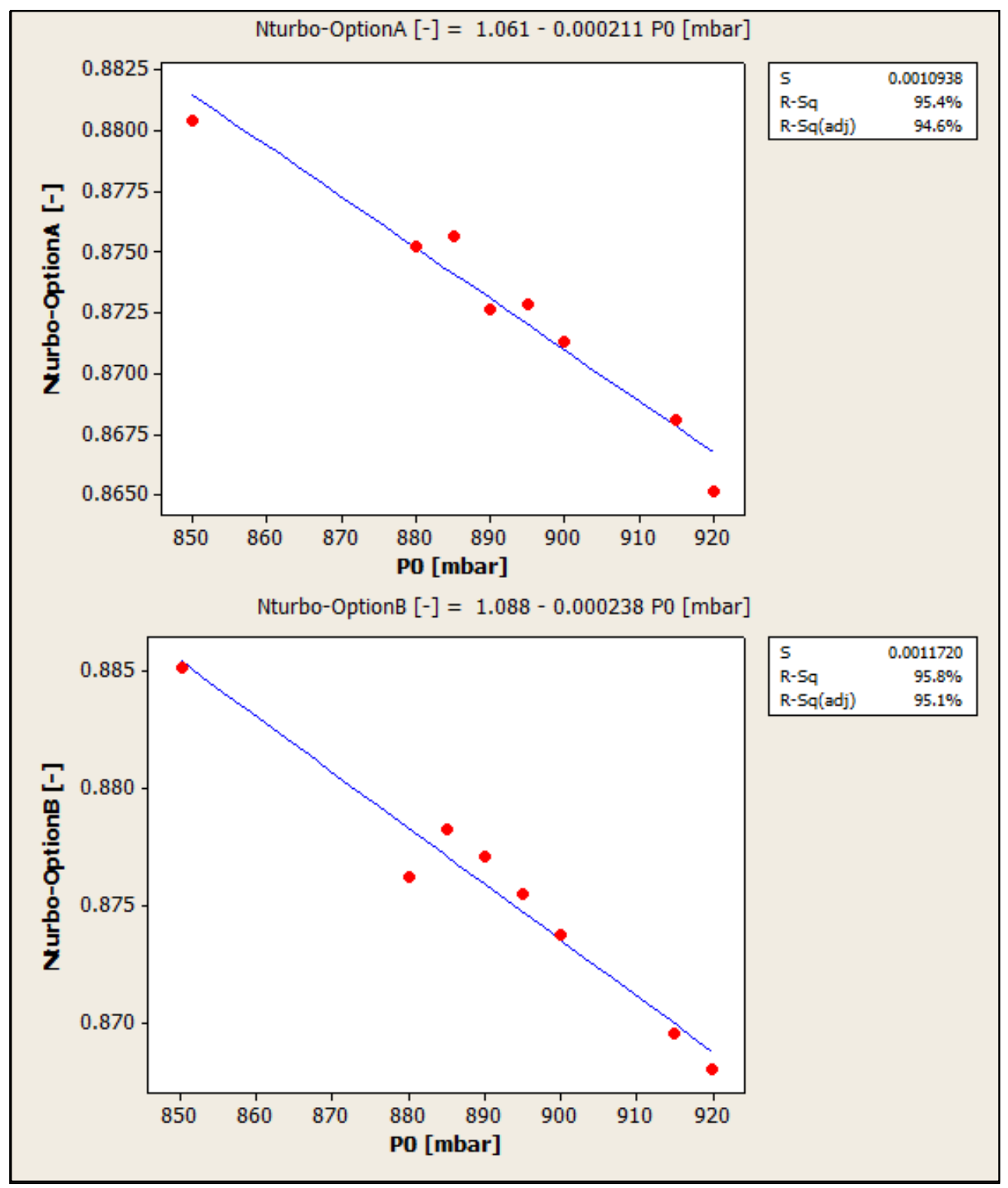

Figure 7: Linear models for both impeller options, presenting r-squared of more than $90 \%$. 


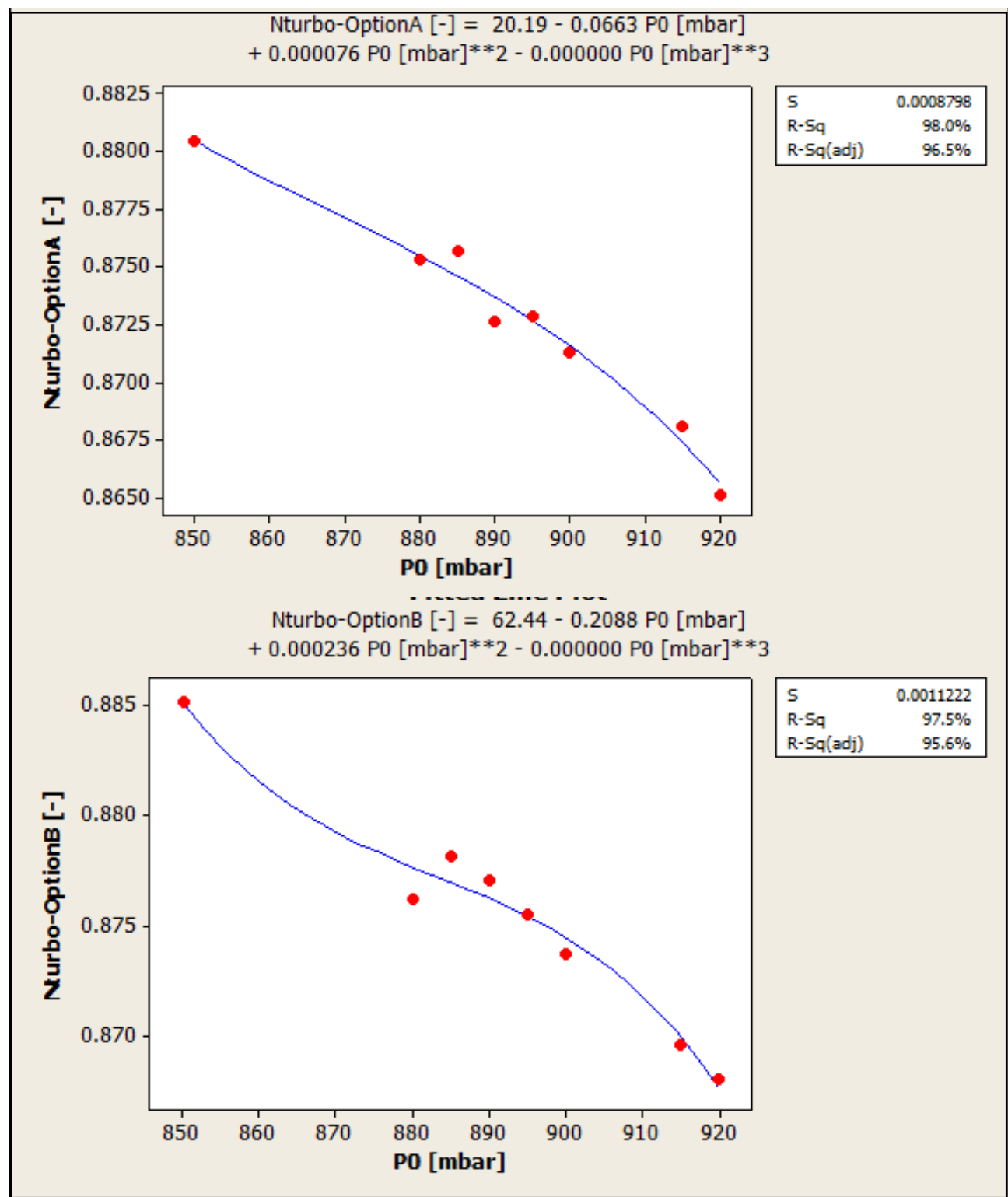

Figure 8: Cubic models for both impeller options, presenting r-squared of more than $90 \%$.

As can be seen, both linear and cubic models fit within the $>90 \%$ criteria, and show acceptable proximity with the logged data. The linear model aids the decision to proceed with the correction factor calculation, as the expected turbocharger shaft speed behavior during altitude variations should be approximately constant. Table 2 shows a summary of r-squared factors.

Table 2: Summary of 'r-squared' factors.

\begin{tabular}{|c|c|c|}
\hline \multicolumn{3}{|c|}{ R-squared (adjusted) } \\
\hline Model & Linear & Cubic \\
\hline Option A & $94.6 \%$ & $96.5 \%$ \\
\hline Option B & $95.1 \%$ & $95.6 \%$ \\
\hline
\end{tabular}

The calculation of the correction factor (increase) for maximum turbocharger shaft speed during altitude variation follows the equation 2 below: 


$$
\text { Corr. factor }=\frac{1000}{n_{930 m}} \cdot \frac{\Delta \mathrm{n}_{\text {turbo }}}{\Delta \text { Altitude }}
$$

Finally, for the correction factor for both impeller options:

$$
\begin{aligned}
& \text { Corr. factor }_{\text {option } A}=\frac{1000}{0.866747} \cdot \frac{(0.881510-0.866747)}{(1560-930)} \\
& \text { Corr. factor }_{\text {option } A}=0.027036 \text { or } \mathbf{2 . 7 0 3 6 \% \text { per } \mathbf { 1 0 0 0 m }} \\
& \text { Corr. factor }_{\text {option } B}=\frac{1000}{0.868729} \cdot \frac{(0.885406-0.868729)}{(1560-930)} \\
& \text { Corr. factor }_{\text {option } B}=0.030471 \text { or } \mathbf{3 . 0 4 7 1} \% \text { per } \mathbf{1 0 0 0 m}
\end{aligned}
$$

\section{CONCLUSION}

The objective of this study was to provide a comparison for two choices of materials and check the maximum speed behavior with the variation of altitude during experimental tests. For this data acquisition was used a delivery truck with a GVW of 8 tons, equipped with 4cylinder engine, while traveling on a route from Guarulhos (ca. 650m alt.) up to Campos de Jordao (ca. 1700m alt.) in the state of Sao Paulo, Brazil. Two different turbochargers were prepared, just changing the impeller option.

During the altitude trip towards Campos de Jordao the altitude ranged from 650m up to $1650 \mathrm{~m}$, although only the uphill sector was considered, because of almost constant steepness from $930 \mathrm{~m}$ up to $1600 \mathrm{~m}$.

The data from both trips were analyzed and a linear model was used to describe the logged points, with accuracy higher than 94.6\%. These curves were used to calculate turbocharger shaft speed increase behavior by influence of the altitude. As could be seen, the Option B (Cast Aluminum impeller) showed a correction factor of $3.0471 \%$ for each $1000 \mathrm{~m}$ of altitude increase. On the other hand, Option A (MFS Aluminum impeller) showed correction factor of $2.7036 \%$ for each $1000 \mathrm{~m}$ of altitude increase. Results are very close to each other, confirming that the impeller option are similar in terms of performance and speed increase by altitude, for the tested application and this specific turbocharger aerodynamic specification.

For further clarifications, please contact:

Fabio Bennaton Bassetti

Cummins Turbo Technologies

Rua Jati, 310 - Cumbica

Guarulhos - SP - 07180-900

Brazil

Tel.: +55 11 2874-3458

E-Mail: fabio.bassetti@cummins.com 


\section{REFERENCES}

[1] ITO, N; OHTA, T.; KONO, R.; ARIKAWA, S.; MATSUMOTO, T. Development of a 4Cylinder Gasoline Engine with a Variable Flow Turbo-charger. SAE paper 2007-010263.

[2] WeStin, F.; ÅngSTROM, H. Calculation Accuracy of Pulsating Flow through the Turbine of SI-Engine Turbochargers - Part 1 Calculations for Choice of Turbines with Different Flow Characteristics. SAE paper 2005-01-0222, 2005, doi:10.4271/2005-01-0222. [3] TAYLOR, C. F. The Internal Combustion Engine in Theory and Practice. 2nd Edition, Revised: Thermodynamics, Fluid Flow, Performance. 1985.

[4] MUKHERJEE, S.; BAKER, D. Thermal Design of High Pressure Ratio Turbocharger Compressor Wheels. SAE paper 2002-01-0162.

[5] Virtual Magazine Cummins Turbo technologies HTi, 7th edition, available at Holset Website: (http://www.holset.co.uk/mainsite/pics-related/3_1-magazines/HTiEdition07.pdf). Accessed on 21/May/2013.

[6] Resolution 403/2008, PROCONVE P7 standards for heavy-duty engines. Brazil, 2008.

[7] ISO 1585:1992

[8] GARCIA, O.; BRUNETTI, F. Motores de Combustão Interna. 2nd Edition.

[9] ALFANO, D. Turbocharger Applications. SAE Technical Paper 862051, 1986, doi:10.4271/862051.

[10] MARSIGLIA, R.; BASSETTI, F. Thermodynamic Evaluation of Two-Stage Turbocharging System. SAE Technical Paper 2012-36-0169, 2012, doi:10.4271/2012-360169. 